\title{
SUBPERIOSTEAL GANGLION
}

\author{
A CASE REPORT \\ W. J. GRANGE \\ From the Royal Air Force Hospital, Ely, Cambridgeshire
}

\begin{abstract}
A case of a subperiosteal ganglion is presented showing an unusual radiological picture. The differential diagnosis of these appearances is discussed.
\end{abstract}

A periosteal ganglion is rare. Since the original description in the middle of the last century by Poncet (1874), only isolated cases have been reported (Fisk 1949; Byers and Wadsworth 1970). So far as the author is aware, no previous report of a subperiosteal ganglion with the radiological changes to be recorded here has been published. The radiological picture, with spicules of bone with terminal expansions giving a honeycombed appearance, is striking, and it can probably be regarded as diagnostic of the condition. Previous reports have stressed the concavity in the cortex produced by ganglia attached to the periosteum, but in this case the depression caused was slight and the major change was the outgrowth of cortical bone. It is suggested that this is due to the unusual site of the ganglion deep to the periosteum (Byers and Wadsworth 1970).

\section{CASE REPORT}

An airman aged thirty-nine presented with an injury of the right wrist. A radiograph showed a fracture of the styloid process of the ulna. It also revealed a periosteal reaction and underlying cortical erosion of the radius, which was obviously of some long duration although it had not caused any symptoms (Fig. 1).

Findings at operation. Because the nature of the lesion was in doubt the area was explored. Upon division of the skin a ganglion was found showing through the raised periosteum. The overlying periosteum was removed, revealing a honeycombed swelling containing locules of the ganglion in the spaces. The ganglion and a sliver of the cortex of the radius were excised. The histological picture was that of a simple ganglion, lying beneath rather than within the periosteum. This is at variance with the experience of Byers and Wadsworth.

\section{DISCUSSION}

Many benign tumours of periosteal origin can produce underlying bone changes (Lichtenstein 1955). These usually consist of a trough-like hollow in the cortex of the bone, presumably formed by pressure. A few tumours produce more reaction than this: a periosteal chondroma (Lichtenstein and Hall 1952) may cause a semilunar hollow in the cortex, with a base of sclerotic bone. Sometimes focal areas within the soft tissue mass are calcified or ossified, and thus visible in the radiographs. A chondroma is usually lobulated, giving an uneven margin to the underlying cortical bone.

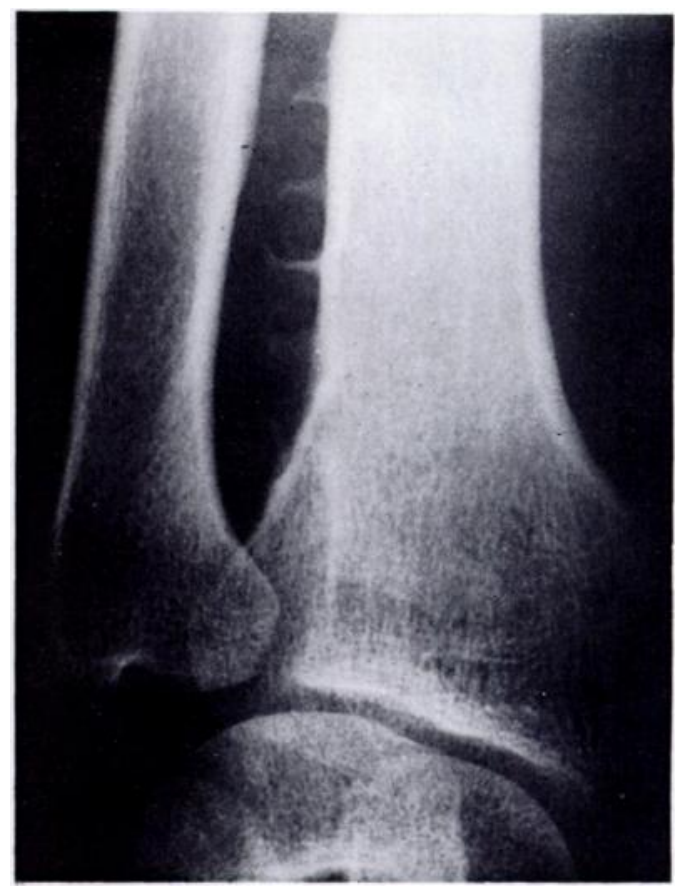

Fig. 1

Radiograph of the right wrist showing the changes associated with a subperiosteal ganglion.

Fleming, Alpert and Garcia (1962) described the salient features of parosteal lipomata. Many of these show little in the way of bony changes, but there may be an overproduction of cortical bone as well as an erosion at the site of abutment of the tumour onto the bone. Fine linear streaks representing fibrous connective septa are 
usually seen in the soft tissue mass, which may also contain areas of calcification. Similarly, a giant cell tumour of tendon sheath may erode the bone by pressure, but little reaction of the bone occurs (Phalen, McCormack and Gazale 1959).

Parosteal osteosarcomata usually present when the tumour has begun to encircle the bone. The typical radiological appearance of a dense lobulated mass surrounding a long bone is well known (Unni et al. 1976). The tumour is attached by a stalk to the bone, and in the early stages a raised dense area lifting off the surface of the bone is seen with rather ill-defined edges.

Most periosteal tumours with radiological bony changes produce a concavity in the cortex with a minor amount of periosteal reaction. In the case described here the predominant radiological change is of spicules of bone arising from the radial cortex, with only minor erosive changes. This striking radiological appearance may be specific for a subperiosteal ganglion, allowing a positive diagnosis before operation. At present, however, open biopsy of such a lesion must be considered prudent.

The author is grateful to Wing Commander T. J. P. Bucher, R.A.F., and Mr J. Crawford Adams for their help in the preparation of this report. $\mathrm{He}$ is indebted to the Director General of Medical Services, Royal Air Force, for permission to publish this case.

\section{REFERENCES}

Byers, P. D., and Wadsworth, T. G. (1970) Periosteal ganglion. Journal of Bone and Joint Surgery, 52-B, 290-295.

Fisk, G. R. (1949) Bone concavity caused by a ganglion. Journal of Bone and Joint Surgery, 31-B, 220-221.

Fleming, R. J., Alpert, M., and Garcia, A. (1962) Parosteal lipoma. American Journal of Roentgenology, Radium Therapy and Nuclear Medicine, 87, 1075-1084.

Lichtenstein, L. (1955) Tumors of periosteal origin. Cancer, 8, 1060-1069.

Lichtenstein, L., and Hall, J. E. (1952) Periosteal chondroma. Journal of Bone and Joint Surgery, 34-A, 691-697.

Phalen, G. S., McCormack, L. J., and Gazale, W. J. (1959) Giant-cell tumour of tendon sheath (benign synovioma) in the hand. Clinical Orthopaedics, 15, 140-151.

Poncet, M. A. (1874) De la périostite albumineuse. Gazette hebdomadaire de médecine et de chirurgie, 11, 133-135, $179-181$.

Unni, K. K., Dahlin, D. C., Beabout, J. W., and Ivins, J. C. (1976) Parosteal osteogenic sarcoma. Cancer, 37, 2466-2475. 